\title{
Preconceito no Brasil Contemporâneo: as Pequenas Diferenças na Constituição das Subjetividades ${ }^{1}$
}

Prejudice in Today's Brazil: the Small Differences in the Subjectivities Constitution

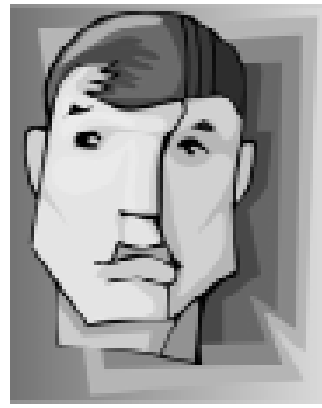

Sérgio Gomes da Silva

Psicólogo clínico graduado pela UFPB.

Especialista em sexualidade humana pelo Centro de

Educação/UFPB e especialista em direitos humanos pelo

Departamento de Filosofia/UFPB.
Resumo: Ao compreender o preconceito como um conjunto de crenças, atitudes e comportamentos negativos atribuídos a membros de determinados grupos sociais, o objetivo do presente trabalho é analisar o preconceito contra as minorias negras e homoeróticas, a partir de uma leitura da Psicologia Social e freudiana, verificando qual a saída mais ética para esse mal-estar que ainda se vivencia na contemporaneidade.

Palavras chave: Preconceito, subjetividade, narcisismo.

Abstract: Understanding prejudice as a set of negative beliefs, attitudes and behaviors attributed to members of social groups, the objective of the present work is to analyze the prejudice against black people and homoerotics, from a Social Psychology and freudian point of view, to verify which is the most ethical solution for this malaise present in the contemporary days.

Key-Words: Prejudice, subjectivity, narcissism.

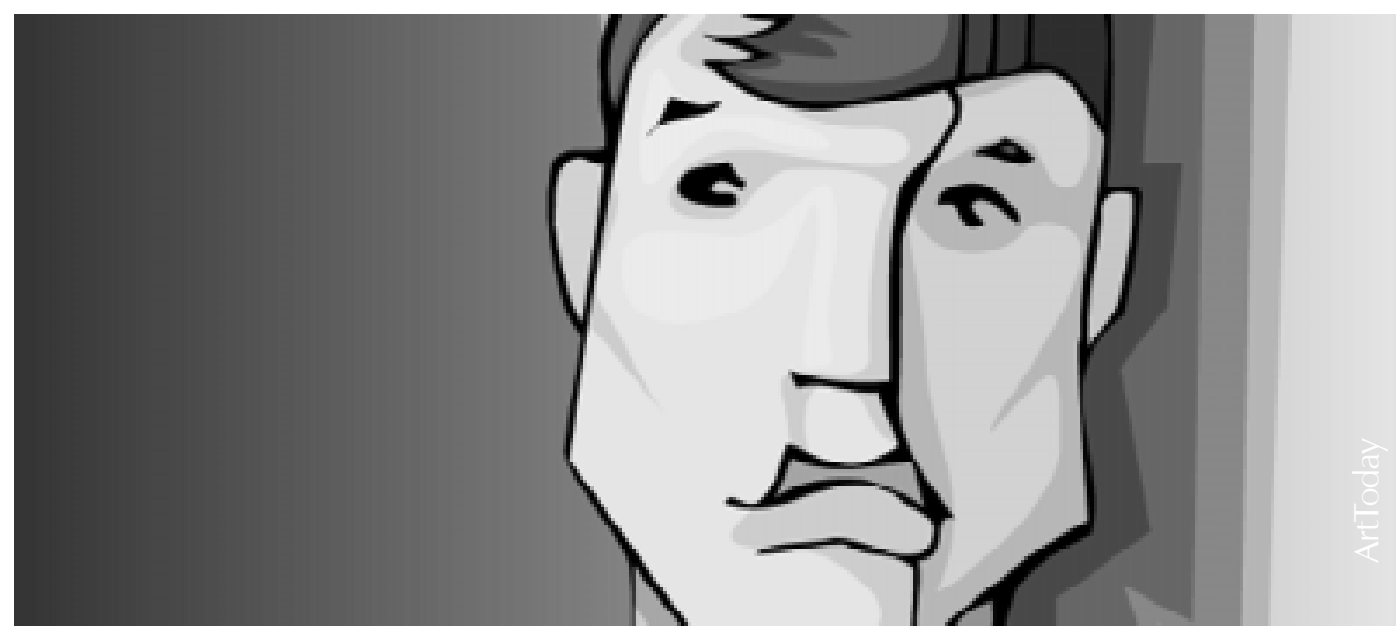

Conceber o outro como um dos nossos semelhantes parece cada vez mais difícil em nossa cultura. $\mathrm{Na}$ contemporaneidade, nossos traços físicos e nossa sexualidade ainda são alvos de discriminação e preconceito, principalmente quando entendemos esses traços desqualificadores como pertencentes a minorias.

Com essa questão em mente, resolvemos discutir algumas questões relativas ao "narcisismo das pequenas diferenças" postulado por Freud (1930/ 1969), tomando como base o debate promovido pela tese do antropólogo Luiz Mott, em 1995, acerca da possível homossexualidade do líder negro Zumbi dos Palmares, frente a grupos do movimento negro e homossexual no Brasil.

A partir dessas considerações, perguntamos: por que a homossexualidade de Zumbi não foi aceita pelos grupos do movimento negro, e por que não houve uma reação semelhante por parte de grupos homossexuais? O que é pior em nossa sociedade: ser identificado como negro ou como homossexual? E quando se passa a pertencer a ambos os grupos, significa ser discriminado duplamente?

Parece-nos que adentramos o século XXI sob o legado do preconceito contra duas minorias sociais que há tempos vêm sendo discriminadas: o homossexual e o negro.

Preconceito "é o conjunto de crenças, atitudes e comportamentos que consiste em atribuir a qualquer membro de determinado grupo humano uma característica negativa, pelo simples fato de pertencer àquele grupo: a característica em questão é vista como adere indelevelmente a todos os indivíduos que o compõem" (MEZAN, 1998, p. 226).

Porém, para Jones (citado por Goldstein, 1983), autor ligado à Psicologia Social, o preconceito é definido essencial, definidora da natureza do grupo, e portanto 
como "um julgamento negativo dos membros de uma raça ou religião, dos ocupantes de qualquer outro papel social significativo, uma avaliação não válida de um grupo ou de seus membros, ou ainda uma atitude ou sentimento que predispõe o indivíduo a atuar, pensar e sentir de modo desfavorável sobre outra pessoa ou objeto" (p. 50).

Aqui vemos Zumbi, líder dos negros no Brasil Império, e "portador", sob a ótica de Mott, do "rótulo" de homossexual. A representação de Zumbi para os negros tem um valor muito maior pelo seu traço de líder. Ser líder é um fator preponderante para a existência do grupo, porém não o único.

Para que um grupo exista, também se faz necessário que seus integrantes se identifiquem com os ideais do grupo que, em sua maioria, são predominantemente responsabilidade do seu líder. Quando esse líder tem sua imagem "associada à homossexualidade", o preconceito contra a figura do Zumbi homossexual se sobressai como em um modelo gestaltista em que Zumbi homossexual é figura e Zumbi negro é fundo.

Não obstante, ambos os preconceitos têm sua respectiva gênese.

O homossexualismo não era algo passível de preconceito na Grécia antiga. Aliás, amar o mesmo sexo era privilégio apenas dos homens. Segundo Costa (1989), "o homossexualismo masculino se inseria em um contexto significativo que impedia o homem grego de pensar no ato homossexual como uma coisa aberrante, doente, anormal, criminosa ou vergonhosa. Dentro de certos limites e em certas condições, a relação homossexual era perfeitamente admitida (...) a construção da identidade psicológica do grego não fazia da heterossexualidade o predicado definitório da essência do eu universal do homem" (p. 23).

Foi apenas com a preocupação médico-psiquiátrica no final do século XVIII que se procurou diagnosticar "homossexualismo" como doença patológica, portanto, curável, começando a fomentar o preconceito. Esse tipo de preconceito se arrastou até os dias atuais, atravessando movimentos culturais, como os de liberdade, paz e amor livre (nos Estados Unidos, contra a Guerra do Vietnam) e os movimentos estudantis (no Brasil, contra o regime militar).

Porém, o preconceito contra homossexuais se fomenta ainda, conforme Fry e MacRae (1985), nos paradigmas dos papéis sexuais entre pessoas do mesmo sexo como, por exemplo, a dicotomia machista "ativo/passivo", "dominador/dominado", que propunha uma nova identidade homossexual nas relações afetivo-sexuais.

Outro ponto que fomenta o preconceito contra homossexuais foi levantado por Costa $(1992,1995)$, no atributo e uso da linguagem usada desde o final do século XVIII, que vê na palavra homossexual/ homossexualismo algo pejorativo em relação a figuras de pessoas homoeróticas. O termo homoerótico/ homoerotismo foi criado por F. Karsh-Haak em 1911, e usado por Sandor Ferenczi no mesmo ano, ao criticar a Psicanálise. Apesar disto, Freud (1907/1969) fez uso do termo em seu Três Ensaios sobre a Teoria da Sexualidade. Para Costa (1992), o termo homoerótico/homoerotismo descreve melhor a pluralidade das práticas e desejos sexuais dos homens "same-sex-oriented" ${ }^{2}$ e nega a idéia de uma "substância" homossexual orgânica com tendências homoeróticas. Sempre que usamos a palavra homossexual/homossexualismo, evocamos, querendo ou não, o contexto de crença preconceituosa que até hoje faz parecer natural dividirmos homens e mulheres em homo e heterossexuais. O indivíduo identificado como homossexual dificilmente consegue proteger sua privacidade sexual no espaço público pelo simples fato de ser sistematicamente interpelado em nome da sua preferência erótica.

Além desse, houve outro marco que forçosamente contribuiu para o fomento do preconceito contra homossexuais: o advento da AIDS, no início da década de 1980, quando se passou a desqualificar o doente não porque este fosse portador de um vírus que o levaria a um fim evidente, mas porque este foi associado imediatamente à sua escolha afetivosexual.

No caso dos negros, o fomento do preconceito ocorreu de forma diferente, a partir de sua entrada em nosso país através da exploração da mão-deobra escrava.

Após sua libertação, os negros ficaram à mercê da sociedade "predominantemente" branca, em busca de uma identidade própria.

O racismo traz, na sua genealogia, um processo de negação ao considerar que homens e mulheres sejam diferentes daquilo que se convencionou chamar de maioria branca, apenas pelo caráter hereditário e tom da pele.

De acordo com Mezan (1998), "podemos dizer que o racismo é a forma que assume o preconceito quando o grupo portador das características repugnantes ou indesejáveis é uma raça, e não uma profissão, uma corrente de opinião, os moradores de certa região ou localidade etc. (...) Por trás da aparente tautologia - o racismo é o preconceito contra uma raça - oculta-se um complexo problema, que é o da própria conceituação do que seja uma 'raça'". O autor ainda vai afirmar que "esta noção surgiu com os progressos da biologia do século XIX, tendo de início a aparência de um conceito epistemologicamente tão sólido quanto os de célula ou de tecido; contudo, desde cedo ele se prestou a uma utilização ideológica, no sentido de
"Desde a inquisição,

atrovés da

penitenciária, do

exame de

consciência, da

direção espiritual, da

educação da

Medicina, da

higiene, da

Psicanálise e da

Psiquiatria, a

sexualidade foi

sempre suspeita de

deter sobre nós uma

verdade decisiva e

profunda. Dize-nos o

que é teu prazer, não

nos esconda nada

do que se passa

entre teu coração e

teu sexo: nós

saberemos o que tu

és e te diremos o que vales".

Michel Foucault, Ditos e Escritos I, p. 291

10 presente artigo resulta da monografia de Graduação em Psicologia, elaborada durante os dois semestres de 1995. Este trabalho foi apresentado no XXVI Congresso Interamericano de Psicologia, de 06 a 11 de julho de 1997, sob o título de "Preconceito no Brasil Contemporâneo: O Caso Zumbi dos Palmares", PUC-SP, São Paulo-SP, Resumo nos Anais do Congresso, p. 289. A presente versão é inédita, e foi modificada para publicação. Agradeço à Profa. Maria Teresa Barreto de Melo Campelo pela orientação deste trabalho, à época em que foi realizado, eo seu incentivo na formação acadêmica do pesquisador: Este artigo, só agora publicado, é dedicado a ela.

2 "Orientada para o mesmo sexo". 
diferenciar as raças humanas numa escala com graus inferiores e superiores" (p. 227).

Costa (1986), ao retomar as palavras de Marilena Chauí, concorda que "ser negro é ser violentado de forma constante, contínua e cruel, sem pausa ou repouso, por uma dupla injunção: a de encarnar o corpo e os ideais do ego do sujeito branco e a de recusar, negar e anular a presença do corpo negro" (p. 104).

Ora, à sociedade branca coube a tarefa de destruir a identidade do sujeito negro em prol de um ideal de ego branco. O ideal de ego é "um produto formado a partir de imagens e palavras, representações e afetos que circulam incessantemente entre a criança e o adulto, favorecendo o surgimento de uma identidade do sujeito compatível com o investimento erótico do seu corpo e de seu pensamento" (COSTA, 1986, p. 103).

Os negros "abdicam", de certa forma, de um ideal de ego negro por um ideal de ego branco ao deixarem de se valorizar em prol de um "produto cultural" da maioria branca. Isso os leva a procurar algo que não condiz com o seu corpo, caracterizando o estado de alienação de sua própria identidade. É a partir dessa subversão de ideal de ego branco que os movimentos anti-racistas lutam contra esse estado de alienação e, por conseguinte, tentam resgatar sua cultura, seus costumes, seus valores.

"ser negro é ser violentado de forma constante, contínua e cruel, sem pausa ou repouso, por uma dupla injunção: a de encarnar o corpo e os ideais do ego do sujeito branco e a de recusar, negar e anular a presença do corpo negro"
Assim, pertencer a ambos os grupos significa ser discriminado duplamente? Mantenho a pergunta. Ainda hoje, penso que somos identificados enquanto indivíduos por nossos traços e estereótipos, persistindo a valorização das nossas diferenças e não das nossas igualdades.

Quando discriminamos sujeitos homoeróticos, isso acontece porque não aceitamos a idéia de que esses sujeitos possam amar e gozar com pessoas do mesmo sexo. Quando discriminamos sujeitos negros, isso acontece porque não admitimos que pessoas iguais a nós possuam um traço físico desqualificador diferente daquilo que ousamos chamar de maioria.

No caso dos indivíduos que participam ao mesmo tempo dessas duas minorias, eles têm sua identidade duplamente ameaçada: a de encarnar no corpo o sofrimento de ser um sujeito discriminado pela escolha afetivo-sexual, e sofrer por toda a conotação negativa, calcada no perverso do final do século XVIII, ao passo que também são indivíduos sem escolhas, oprimidos, que perdem suas identidades e buscam o prazer via gozo e não desejo, vivendo em uma concepção ética e moral calcada na época escravocrata e nas concepções burguesas do período vitoriano.

Remetermos a discursos desse tipo parece não nos levar a lugar algum enquanto caminhamos em busca de uma sociedade mais justa, mais ética e menos preconceituosa. Quando nos prendemos a essas do nosso semelhante alguém muito diferente de nós,

persistimos em uma valorização das nossas pequenas diferenças e não das nossas igualdades. A esses "sintomas sociais", onde um predicado físico, sexual, racial, enfim, qualquer tipologia que nos faça crer que somos diferentes devido a esses traços, Freud (1930/1969) denominou de narcisismo das pequenas diferenças, referindo-se às pulsões de agressividade dirigidas à minorias sociais.

Ropa (1994) vai afirmar que o narcisismo das pequenas diferenças designa uma idéia de pertencimento e exclusão a um determinado grupo ou comunidade, onde o grupo tende a afirmar uma unidade em confronto e oposição a outros grupos, criando-se um mito de superioridade, um fechamento identitário do "nós" diante dos "outros". Aliado a isso, temos o sentido de intolerância e crueldade contra aqueles concebidos como estranhos, diferentes, que não se adequam às normas estabelecidas pela maioria branca, heterossexual, burguesa, capitalista, individualista e narcísica, quando passamos a discriminar indivíduos por suas particularidades ou singularidades físicas, anatômicas, genéticas, sociais, identitárias ou sexuais.

Kehl (1996) complementa nossos argumentos afirmando que "o narcisismo, modo de satisfação privilegiado das pulsões do eu, tolera mal a convivência com o diferente - daí o caráter totalmente reativo do mandamento "ama o próximo como a ti mesmo!" mas suporta menos ainda o confronto com o minimamente diferente, aquele que ameaça não apenas o campo da satisfação das necessidades vitais dos sujeitos como o das identificações, o campo imaginário em que o eu constitui os atributos que compõem o narcisismo secundário" (p. 14).

Quando pensamos em tomar as nossas diferenças como traços desqualificadores reais de uma chamada pretensa maioria, parece que estamos caminhando em um jogo tautológico sem fim, onde ser negro ou ser homossexual possa desqualificar ou desmerecer um sujeito em nossa sociedade. Mas, se tentarmos pautar as nossas idealidades na crença de que existe um outro igual a nós, indiferentes aos traços que tanto aprendemos através da história a desqualificar, além de tomarmos o nosso pertencimento a grupos como um modelo de comunidades ideais compostas de homens e mulheres que poderão pautar sua vida no desejo de solidariedade, conforme postula Rorty (1992, 1997), talvez tenhamos esperança de que essas diferenças possam nos tornar mais tolerantes e nos levar a reconhecer o outro como "um de nós", entendendo esse "nós" como um número cada vez maior de pessoas (CAMPELLO, 1995)

Assim, quando retomamos a polêmica em torno do líder negro Zumbi, passamos a entender melhor o quanto cair em discursos dessa natureza, como homossexualidade ou racismo, é cair no erro de pensar que ser homossexual sugere ser pior do que ser negro, e ser negro e ser homossexual é sofrer duplamente. 
Enquanto negro, Zumbi é herói de negros e brancos. Enquanto homossexual, Zumbi se presta a herói de bem poucos. Enquanto "possível" homossexual, ele cai no rol da mesma medicina psiquiátrica que classificou homens e mulheres em homo e heterossexuais e que também diagnosticou a AIDS, no início dos primeiros casos registrados, como uma doença relativa a homossexuais masculinos.

Tentar compreender porque uma singularidade sexual possa existir a partir de uma tipicidade genética, conforme tentam fazer crer alguns cientistas da mesma ordem médica que classificou e rotulou os homossexuais em indivíduos passíveis de cura, e que diagnosticou a AIDS no início dos anos 1980 como um "câncer gay", é desconsiderar qualquer motivo moral como razão suficiente para exigir a consideração que thes é devida. Da mesma forma, quando os sujeitos negros tentam pautar seus direitos em singularidades físicas, parece que os direitos de buscar um valor moral vão "por água abaixo". Por outro lado, quando o argumento que tivermos diante de nós for de ordem moral e ética, provavelmente possamos compreender que não existem singularidades físicas, sexuais, genéticas ou outras quaisquer que nos façam acreditar que temos de ser intolerantes com esses sujeitos, e passemos a sustentar nosso estar no mundo entre iguais.

É justamente reconhecendo o outro como um de nós, em um número cada vez maior, indiferente às suas diferenças, que talvez possamos chegar a nos reconhecer mais como homens e mulheres do que como seres que só são reconhecidos pelos seus traços desqualificadores. Foi o que Rorty (1992) propôs com o seu "ideal de auto-enriquecimento", que diz: "não pergunte qual o meu verdadeiro eu, o que de essencial existe em mim"; pergunte-me, reconhecendo como critério único o da ética, como homens e mulheres podem descrever a si mesmos, de modo que possam viver uma vida mais feliz e mais harmônica.

Segundo Costa (1994), "o indivíduo que se descreve a partir desse ideal esforça-se por imaginar como novas descrições podem reorientar, de um modo mais satisfatório, aquilo que vive como insatisfação, mal-estar, medo, desespero, sofrimento ou simplesmente vontade de expandir a capacidade de ser feliz" (p. 21).

Na verdade, para que continuemos a caminhar frente à perspectiva de um futuro mais promissor, moral, ético, social etc., devemos aprender a respeitar nossas diferenças.

Acredito que produzir discursos que possibilitem diminuir o preconceito contra os excluídos, homossexuais, negros, pobres, mendigos, índios, judeus, enfim, todos aqueles que não podem participar deste mundo como sujeitos iguais aos outros, e ampliar e justificar nossa tolerância e o nosso "estar no mundo" entre iguais, sejam saídas para um futuro mais promissor, mais ético, mais justo, mais humano, menos caótico. "não pergunte qual o meu verdadeiro eu, o que de essencial existe em mim"

Rorty
Sérgio Gomes da Silva

UFPB - PRPG - Prédio da Reitoria - $2^{\circ}$ Andar - Campus Cidade Universitária - João Pessoa - PB - 58059-900. Tel.: (083) 9987-3097 Email:sergiogsilva1@bol.com.br
CAMPELLO, M. T. de M. B. As pequenas diferenças: traços do real na constituição das subjetividades contemporâneas. In: JORNADADO CÍRCULO PSICANALÍTICO DE PERNAMBUCO, 12., 1-3 dez., 1995, Recife. Anais... Recife: [s.n.], 1995.

COSTA, J. F. Violência e psicanálise. Rio de Janeiro: Graal, 1986.

COSTA, J. F. Psicanálise e contexto cultural: imaginário psicanalítico, grupos e psicoterapias. Rio de Janeiro: Campus, 1989.

COSTA, J. F. A inocência e o vício: estudos sobre o homoerotismo. Rio de Janeiro: Relume-Dumará, 1992.

COSTA, J. F. A face e o verso: estudos sobre o homoerotismo II. São Paulo: Escuta, 1995.

COSTA, J. F. (Org.). Redescrições de psicanálise: ensaios pragmáticos. Rio de Janeiro: Relume-Dumará, [19-].

FOUCAULT, M. Ditos e escritos I - problematização do sujeito: psicologia, psiquiatria e psicanálise. Rio de Janeiro: Forense Universitária, 1999

FREUD, S. O mal-estar na civilização [1930]. Rio de Janeiro: Imago, 1969. v. 21. (Standart Brasileira, Obras Completas).
FREUD, S. Três ensaios sobre a teoria da sexualidade. [1905]. Rio de Janeiro: Imago, 1969. v. 7. (Standart Brasileira, Obras Completas).

Referências bibliográficas

FRY, P.; MACRAE, E. O que é homossexualismo? São Paulo: Abril Cultural, 1985

GOLDSTEIN, J. Psicologia social. Rio de Janeiro: Guanabara, 1983.

KEHL, M. R. A mínima diferença: masculino e feminino na cultura. Rio de Janeiro: Imago, 1996.

MEZAN, R. Tempo de muda: ensaios de psicanálise. São Paulo: Cia das Letras, 1998.

ROPA, D. Ela é... o que você quiser. In: COSTA, J. F. (Org.). Redescrições de psicanálise: ensaios pragmáticos. Rio de Janeiro: Relume-Dumará, 1994.

RORTY, R. Contingência, ironia e solidariedade. Lisboa: Presença, 1992.

RORTY, R. Objetivismo, relativismo e verdade: escritos filosóficos I. Rio de Janeiro: Relume-Dumará, 1997. 